\title{
HEPATOPROTECTIVE EFFECTS OF PUNICA GRANATUM FRUIT AGAINST D-GALACTOSAMINE INDUCED HEPATOTOXICITY IN RATS: IN VITRO AND IN VIVO STUDIES
}

\author{
MOHD AMIR ${ }^{1,2}$, MOHD NASAR MALLICK $^{1}$, NIYAZ AHMAD ${ }^{2}$, ABUZER ALI $^{2}$, SAYEED AHMAD $^{1}$, MOHD AKHTAR $^{3}$, \\ MOHD MUJEEB ${ }^{* 1}$
}

1Bioactive Natural Product Laboratory, Department of Pharmacognosy and Phytochemistry, Faculty of Pharmacy, Jamia Hamdard, New Delhi 110062, India, ${ }^{2}$ College of Clinical Pharmacy, University of Dammam, Dammam 31441, Kingdom of Saudi Arabia, ${ }^{3}$ Department of Pharmacology, Faculty of Pharmacy, Jamia Hamdard, New Delhi 110062, India

Email: drmmujeeb12@gmail.com

Received: 13 Mar 2017 Revised and Accepted: 30 Jun 2017

\begin{abstract}
Objective: Hepatoprotective activity of Punica granatum Linn. (Family: Punicaceae) was evaluated by in vitro and in vivo model. HepG2 cell lines were used for in vitro study and D-Galactosamine (D-GalN) induced hepatic damage model for in vivo evaluation.

Methods: Hepatoprotective potential was assessed by measuring serum level of glutamate oxaloacetate transaminase, glutamate pyruvate transaminase, alkaline phosphatase, total bilirubin, and albumin. Enzymatic antioxidant parameters like TBARs (thiobarbituric acid reactive substances), GSH (glutathione), SOD (superoxide dismutase) and CAT (catalase) also evaluated in this study.

Results: Rats treated with D-GalN showed a significant increase in serum levels of SGOT (serum glutamate oxaloacetate transaminase), SGPT (serum glutamate pyruvate transaminase), ALP (alkaline phosphatase), bilirubin and TBARs, reflecting liver damage. The in vitro study indicates a beneficial effect of aqueous extract of $P$. granatum in comparison with methanolic extract, on D-GalN induced toxicity to HepG2 cells. On the basis of in vitro study, aqueous extract was selected for in vivo evaluation. The aqueous extract of $P$. granatum significantly reduced the elevated serum biomarkers, indicating the recovery of hepatocellular injury. It was also observed that D-GalN induced a significant decrease in GSH, SOD, CAT, protein, and albumin level were increased on the treatment of the rats with aqueous extract of P. granatum. The findings were also confirmed by histopathological studies. Periportal area and extensive hepatocyte damage and haemorrhage are seen in D-GalN treated group. The portal triad with less degree of inflammatory cell infiltration around the bile duct is seen in P. granatum ( $500 \mathrm{mg} / \mathrm{kg})+(\mathrm{D}$-GalN) treated group.
\end{abstract}

Conclusion: Results of this study revealed that $P$. granatum fruit could afford a significant protection for the alleviation of hepatic toxicity. Possible mechanism may involve its action against oxidative stress.

Keywords: In vitro, Hepatocellular injury, Punica granatum, HepG2, D-galactosamine

(C) 2017 The Authors. Published by Innovare Academic Sciences Pvt Ltd. This is an open access article under the CC BY license (http://creativecommons.org/licenses/by/4.0/) DOI: http://dx.doi.org/10.22159/ijpps.2017v9i8.18449

\section{INTRODUCTION}

The liver is one of the biggest organs in the human body and the chief site for strong metabolism and excretion. So it has a surprising role in the maintenance, performance and regulating homoeostasis of the body. It is concerned with almost all the biochemical pathways to growth, fight against the disease, nutrient supply, energy provision, and reproduction [1]. The main functions of the liver are carbohydrate, protein and fat metabolism, detoxification, secretion of bile, and storage of vitamins. Therefore, to maintain a healthy liver is an essential factor for overall health and well being. But it is continuously and variedly uncovered to environmental toxins, and abused by poor drug habits, alcohol, and prescribed and over the counter drugs which can eventually lead to different liver ailments such as hepatitis, cirrhosis, and alcoholic liver ailment [2,3]. Thus liver diseases are some of the lethal diseases in the world today. They pose a serious challenge to international public health.

Liver injury can be caused by different agents, such as viruses, chemicals, alcohol, and auto-immune diseases [4]. D-Galactosamine (D-GalN) is a well-established hepatotoxicant, it induces a diffuse type of liver injury closely resembling human viral hepatitis [5] and acute self-limiting hepatitis with necrosis, inflammation and regeneration, resembling drug-induced diseases in humans [6]. The toxicity of D-GalN is mainly related to the depletion of uridine pools that are associated with limited ribonucleic acid (RNA) and protein synthesis, thus altering hepatocellular function [7].

Modern drugs have little to offer for the alleviation of hepatic diseases and it is mainly the plant based preparations which are employed for their treatment of liver disorders. World Health Organization (WHO) estimated that around $80 \%$ of the world's population depends on medicinal plants as their primary health care source. The WHO has reported around 21,000 plants are used for medicinal purpose. Of which 2500 species are in India, among these 150 species are used commercially on a fairly large scale [8].

Punica granatum Linn. (Commonly known as Pomegranate) belongs to the Punicaceae family [9]. It is an extensively used medicinal fruit of indigenous systems of medicine and commercial horticultural product which is usually very well adapted to the Mediterranean climate [10]. Pomegranate fruits are consumed fresh or processed as juice, jellies and syrup for industrial production [11-13]. The edible part of the fruit contains extensive amounts of tannins [14], flavonoids [15], acids, sugars, vitamins, polysaccharides and important minerals $[16,17]$. It is proved to have good antioxidant value [18], antibacterial action and anti-inflammatory activity [19] and high power for cancer prevention [20].

In Ayurvedic medicine, the pomegranate is considered "a pharmacy unto itself" and is used as an antiparasitic agent [21], a "blood tonic," [22] and to heal aphthae, diarrhea, and ulcers [23]. P. granatum also serves as a remedy for diabetes in the Unani system of medicine practised in the Middle East and India [24].

But still, no scientific investigation has so far been reported in the literature regarding its action on the liver. Therefore, the present investigation has been designed to study the possible mechanism of fruit extract of $P$. granatum for hepatoprotective activity. In this study, we report the activity of $P$. granatum fruit in D-GalN induced toxicity in HepG2 cells and in a rat model. 


\section{MATERIALS AND METHODS}

\section{Plant collection and identification}

The fresh fruit of P. granatum was collected from Delhi, India and was authenticated at Department of Botany, Jamia Hamdard, New Delhi, India, with a voucher specimen (PG/FP-367) which was deposited in the herbarium of Jamia Hamdard New Delhi.

\section{Chemicals}

All analytical grade chemicals were purchased from SD Fine Chemicals Ltd., Mumbai, India. MEM (minimum essential medium), MTT (3-(4,5-dimethyl thiazol-2-yl)-2,5-diphenyl tetrazolium bromide) were purchased from Sigma-Aldrich (USA). HepG2 cells were obtained from National Centre for Cell Science (NCCS), Pune, India. Silymarin was purchased from Microlabs; Holar, TN, India. DGalN was procured from SRL, Mumbai, India.

\section{Preparation of extracts of P. granatum}

The fruit of $P$. granatum was dried in hot air oven at $40-50{ }^{\circ} \mathrm{C}$ for a week. The dried fruit was powdered using mixer grinder. The accurately weighed powdered sample $(10 \mathrm{~g})$ was extracted in 100 $\mathrm{ml}$ of extraction solvents water and methanol separately. These were kept overnight with occasional shaking and sonicated for 30 min at $25 \pm 3{ }^{\circ} \mathrm{C}$ in an ultra sonicator water bath followed by filtration and drying using rotary evaporator at $40^{\circ} \mathrm{C}$.

\section{Determination of total phenolics and flavonoids contents}

Total phenolic content was determined by Folin-Ciocalteu reagent similar to the method reported by Amir et al., (2011) [25]. The aluminium chloride colorimetric method was used for flavonoids determination as reported [26].

\section{In vitro assay}

In vitro hepatoprotective activity was assessed by the ability of an aqueous and methanolic extract of P. granatum to preclude the oxidative stress induced by D-GalN in HepG2 cells. HepG2 cells were plated at a density of $1 \times 10^{4}$ cells per well in a 96 well plate along with $100 \mu \mathrm{l}$ of MEM supplemented with 10\% FBS (fetal bovine serum) in each well. Various concentrations of aqueous and methanolic extract $(10,20$, and $30 \mu \mathrm{g} / \mathrm{ml}$ ) were exposed to HepG2 cells along with D-GalN ( $50 \mathrm{mmol}$ ) for $8 \mathrm{~h}$ and the viability of cells was assessed by MTT assay. The hepatoprotective effect of the test sample was assessed by the cell viability assay and expressed as percent protection. Silymarin was used as the reference drug at a concentration of $100 \mu \mathrm{g} / \mathrm{ml}$ [27].

\section{Animals}

Wistar albino rats (150-200 g) of either sex were issued from Central Animal House Facility of Hamdard University and acclimatized for a week under standard housing conditions maintained at a room temperature of $24 \pm 1{ }^{\circ} \mathrm{C}$; relative humidity $45-55 \%$ with $12: 12 \mathrm{~h}$ light and dark cycle. The institutional animal ethics committee of Hamdard University, New Delhi, India, approved the experimental protocol in accordance with the guidelines provided by Committee for the Purpose of Control and Supervision of Experiments on Animals (CPCSEA) with registration number 173/CPCSEA.

\section{Acute toxicity}

Acute toxicity study of aqueous extract was determined as per the OECD guideline No. 423 [28]. Albino rats were divided into test group comprising of six animals in each group. The test was performed using an increasing oral dose of a herbal extract from $100-3000 \mathrm{mg} / \mathrm{kg}$ body weight [29]. The rats were observed continuously for $1 \mathrm{~h}$ and then half hourly for $4 \mathrm{~h}$ for any gross behavioural change and general motor activities like writhing, convulsion, response to tail pinching, gnawing, pupil size, faecal output, feeding behaviour, etc., and further up to $72 \mathrm{~h}$ for any mortality. The extract does not cause any significant behavioral changes and no mortality was observed. The extract was devoid of any toxicity in rats when given in dose up to $3000 \mathrm{mg} / \mathrm{kg}$ by the oral route.

\section{Hepatoprotective activity}

Albino Rats were randomly divided into five groups of six animals each. Group, I served as normal control and received normal saline $(1 \mathrm{ml} / \mathrm{kg}$, p. o.) for $21 \mathrm{~d}$. Group II served as toxic control and received normal saline
( $1 \mathrm{ml} / \mathrm{kg}$, p. o.) for $21 \mathrm{~d}$. Groups III was prophylactically treated with silymarin $(25 \mathrm{mg} / \mathrm{kg}$, p. o.) for $21 \mathrm{~d}$. Groups IV served as per se group and treated with a higher dose $(500 \mathrm{mg} / \mathrm{kg}, \mathrm{p}$. o.) of aqueous extract of P. granatum for $21 \mathrm{~d}$. Groups V and VI were prophylactically treated with aqueous extract of $P$. granatum $(250 \mathrm{mg} / \mathrm{kg}$ and $500 \mathrm{mg} / \mathrm{kg}$, p. o. $)$ for $21 \mathrm{~d}$, respectively. Groups II, III, V and VI also received D-GalN (400 $\mathrm{mg} / \mathrm{kg}$, i. p.) on $21^{\text {st }}$ day [30]. After $24 \mathrm{~h}$ of D-GalN administration blood was collected from tail vein under light ether anaesthesia. Immediately, after blood withdrawal, all the groups were sacrificed. Liver samples were also collected for histological and biochemical estimations. The blood samples were allowed to clot for 30-40 min. Serum was separated by centrifugation at $3000 \mathrm{rpm}$ for $15 \mathrm{~min}$ and was used for estimation of biochemical parameters. Liver samples collected were washed with chilled normal saline and $10 \%(\mathrm{w} / \mathrm{v})$ liver homogenates were prepared.

\section{Analysis of biochemical parameter in serum}

The activities of serum glutamate oxaloacetate transaminase (SGOT), serum glutamate pyruvate transaminase (SGPT) [31], albumin [32], total bilirubin [33], and alkaline phosphatase (ALP) [34] were assayed.

\section{Analysis of biochemical parameter in hepatic tissue}

Lipid peroxidation (LPO) was determined by measuring thiobarbituric acid reactive substances (TBARS) [35]. Glutathione (GSH) level was determined by using Ellman's reagent method [36]. Superoxide dismutase (SOD) [37], catalase (CAT) [38] was analyzed in homogenate hepatic tissue.

\section{Histological studies}

Livers were quickly removed and preserved in neutral buffered formalin. Histological liver sections were prepared [39], stained and evaluated by a pathologist blind to grouping details.

\section{Data analysis}

Results are expressed as mean \pm SD Total variation present in a set of data was estimated by one-way analysis of variance (ANOVA) followed by Dunnet's post-hoc test. $\mathrm{P}<0.05$ and $\mathrm{P}<0.01$ were considered to be significant.

\section{RESULTS}

The phenolic and flavonoid content in P. granatum was found to be $1.86 \% \mathrm{w} / \mathrm{w}$ and $1.84 \% \mathrm{w} / \mathrm{w}$, respectively. At the dose of 10,20 , and $30 \mu \mathrm{g} / \mathrm{ml}$ of aqueous extract and methanolic extract were used for testing the protective effect on D-GalN induced oxidative damage in the HepG2 hepatic cell line. The results clearly demonstrated that hepatoprotective activity of aqueous extract of $P$. granatum was significant at 20 and $30 \mu \mathrm{g} / \mathrm{ml}$ concentrations $(\mathrm{p}<0.001)$ but not at $10 \mu \mathrm{g} / \mathrm{ml}$ of aqueous extract of $P$. granatum. Maximum protection in $\mathrm{D}$-GalN induced oxidative damage was observed at $30 \mu \mathrm{g} / \mathrm{ml}$ as shown in fig. 1 . There is no significant observation in methanolic extract of the drug. The protective effect of aqueous extract can be explained with its ability to quench free radicals generated by DGalN; therefore aqueous extract was selected for in vivo study.

Table 1 shows the dose dependent preventive effect of aqueous extract of $P$. granatum against D-GalN induced toxicity. Acute exposure to D-GalN caused a significant increase in the activity of SGOT, SGPT, ALP and bilirubin $(\mathrm{P}<0.01)$ into circulation. Treatment with aqueous extract of $P$. granatum at different doses ( 250 and 500 $\mathrm{mg} / \mathrm{kg}$ ) caused a significant reduction in the elevated levels of serum enzymes in a dose-dependent manner $(\mathrm{P}<0.05, \mathrm{P}<0.01)$. The aqueous extract of $P$. granatum significantly decreased the elevated levels of serum albumin $(\mathrm{P}<0.05, \mathrm{P}<0.01)$ towards normal. Aqueous extract of $P$. granatum therapy showed a better response at restoring these serum variables at the higher dose vs lower dose. Table 2 depicts the effect of D-GalN and therapeutic agent on LPO and GSH in the liver. D-GalN induced acute intoxication significantly increased TBARs level $(\mathrm{P}<0.01)$ and significantly decreased GSH content, SOD and CAT in hepatic tissue $(\mathrm{P}<0.01)$. Therapy with aqueous extract of $P$. granatum significantly lowered TBARs level $(\mathrm{P}<0.01)$ and alleviated GSH content, SOD and CAT as seen by statistical analysis $(\mathrm{P}<0.01)$. The observations of comparative histopathological studies of liver from each of the groups of rats are 
given in fig. 2 . Treatment with $P$. granatum was found to be effective in restoring these enzymatic parameters in dose dependent manner.
The $500 \mathrm{mg} / \mathrm{kg}$ dose showed maximum recovery in these enzyme activities in experimental animals.

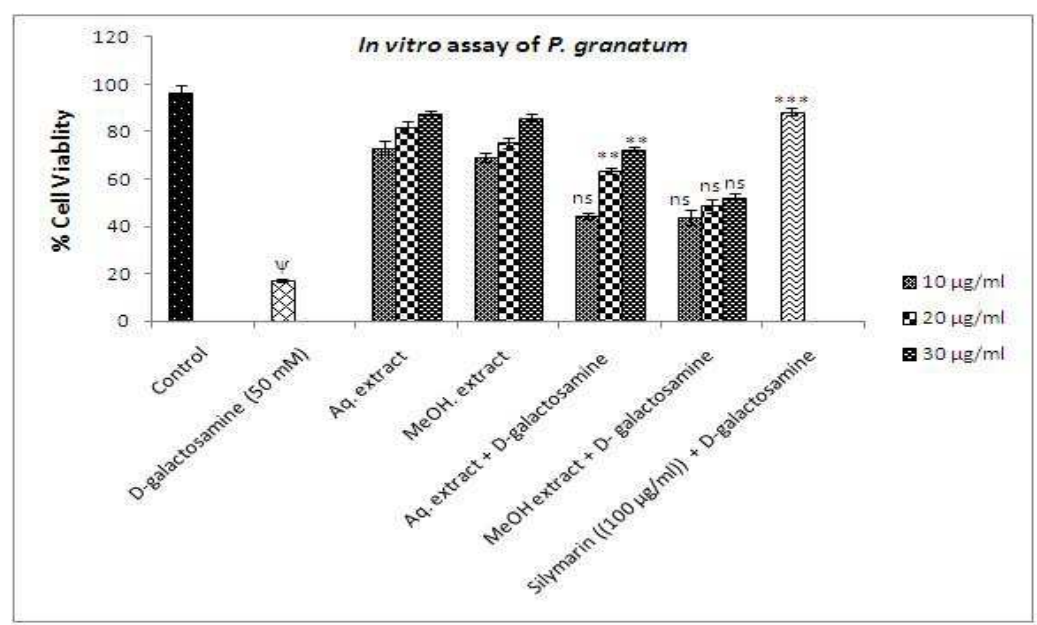

Fig. 1: In vitro hepatoprotective activity of an aqueous and methanolic extract of $P$. granatum fruit on D-galactosamine induced hepatic damage in HepG2 cell line, Aq. Extract (Aqueous extract), $\mathrm{MeOH}$ extract (Methanolic extract), $\mu \mathrm{g} / \mathrm{ml}$ (micrograms per millilitre), mmol (mili mole), Data were presented as mean $\pm S D$, No. of experiment $(n)=6$

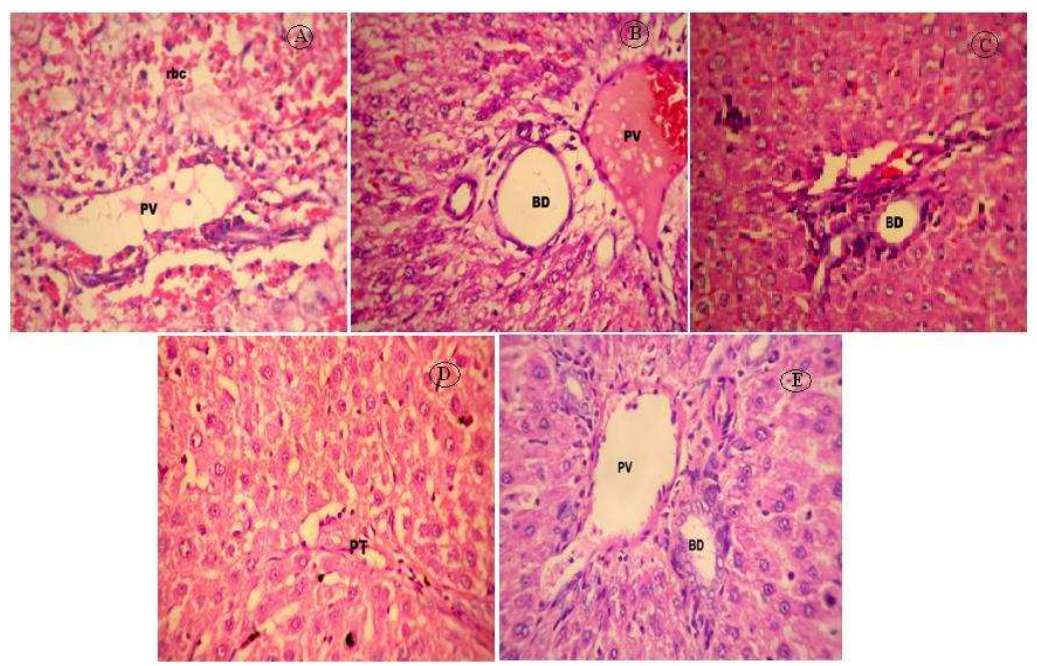

Fig. 2(A): Magnified view of liver from normal control group showing a portal triad with normal structures, PV = Portal Vein, BD = Bile Duct (HE x 400). (B): Magnified view of liver from Toxic Control group showing the periportal area and extensive hepatocyte damage and haemorrhage. PV = Portal Vein (HE x 400). (C): Magnified view of liver from Standard Drug group showing a portal triad and the periportal zone. No evidence of hepatocyte damage is seen (HE x 400). (D): Magnified view of Liver from P. granatum (250 mg/kg)+(DGalN) group showing inflammatory cells in the portal triad (HE x 400). (E) Magnified view of Liver from P. granatum (500 mg/kg)+(DGalN) group showing the portal triad with a moderate degree of inflammatory cell infiltration around the bile duct. $P V=P o r t a l$ Vein, $B D=$ Bile Duct (HE x 400), Data were presented as mean \pm SD, No. of animals $(n)=6$

Table 1: Effects of aqueous extract of Punica granatum on biochemical parameters in serum. Data were presented as mean \pm SD, No. of animals (n) $=6$

\begin{tabular}{llllll}
\hline \multirow{2}{*}{ Groups } & Parameters & & & & \\
\cline { 2 - 6 } & SGOT (IU/l) & SGPT (IU/l) & Albumin (g/dL) & Total bilirubin (mg/dL) & ALP (KA unit) \\
\hline Control & $42.95 \pm 5.36$ & $49.32 \pm 5.75$ & $5.85 \pm 0.064$ & $0.31 \pm 0.04$ & $26.54 \pm 5.96$ \\
Toxic Control (GalN) & $136.55 \pm 11.50^{\Psi}$ & $177.70 \pm 13.33^{\Psi}$ & $3.46 \pm 0.074^{\Psi}$ & $2.34 \pm 0.07^{\Psi}$ & $101.71 \pm 8.73^{\Psi}$ \\
Positive Control (Silymarin) & $48.32 \pm 6.30^{* *}$ & $59.64 \pm 6.19^{* *}$ & $5.75 \pm 0.070^{* *}$ & $0.47 \pm 0.05^{* *}$ & $31.73 \pm 4.39^{* *}$ \\
P. granatum (500 mg/kg) (per se) & $43.86 \pm 4.58$ & $51.65 \pm 5.91$ & $5.81 \pm 0.059$ & $0.35 \pm 0.03$ & $28.73 \pm 5.17$ \\
P. granatum (250 mg/kg)+(GalN) & $121.10 \pm 8.26^{*}$ & $161.47 \pm 10.23^{*}$ & $3.71 \pm 0.35$ & $2.05 \pm 0.13^{*}$ & $85.97 \pm 5.40^{*}$ \\
P. granatum (500 mg/kg)+(GalN) & $69.79 \pm 8.10^{* *}$ & $91.72 \pm 7.58^{* *}$ & $5.28 \pm 0.045^{* *}$ & $0.67 \pm 0.07^{* *}$ & $40.75 \pm 5.29^{* *}$ \\
\hline
\end{tabular}

Significant value: ${ }^{\Psi} \mathrm{P}<0.01$ Vs normal control, ${ }^{*} \mathrm{P}<0.05$; ${ }^{*} \mathrm{P}<0.01$ Vs toxic control, One way ANOVA followed by Dunnett's Test, SGOT (serum glutamate oxaloacetate transaminase), SGPT (serum glutamate pyruvate transaminase), ALP (alkaline phosphatase), IU/l (international units per liter), g/dL (grams per deciliter), KA unit (king armstrong unit). 
Table 2: Effects of aqueous extract of Punica granatum on biochemical parameters in hepatic tissue. Data were presented as mean \pm SD, No. of animals (n) $=6$

\begin{tabular}{|c|c|c|c|c|}
\hline \multirow[t]{2}{*}{ Groups } & \multicolumn{4}{|l|}{ Parameters } \\
\hline & $\begin{array}{l}\text { TBARS (nanomole of } \\
\text { MDA/mg protein) }\end{array}$ & $\begin{array}{l}\text { GSH }(\mu \text { mole GSH } / \mathrm{mg} \\
\text { protein) }\end{array}$ & $\begin{array}{l}\text { SOD (nanomoles of } \mathrm{H} 202 \\
\text { consumed/min/mg protein) }\end{array}$ & $\begin{array}{l}\text { Catalase } \\
\text { (U/mg protein) }\end{array}$ \\
\hline Control & $0.083 \pm 0.006$ & $0.86 \pm 0.23$ & $6.26 \pm 1.07$ & $8.54 \pm 0.67$ \\
\hline Toxic Control (GalN) & $0.212 \pm 0.02^{\Psi}$ & $0.292 \pm 0.10^{\Psi}$ & $1.80 \pm 0.80^{\Psi}$ & $2.05 \pm 0.45^{\Psi}$ \\
\hline $\begin{array}{l}\text { P. granatum }(500 \mathrm{mg} / \mathrm{kg}) \\
\text { (per se) }\end{array}$ & $0.084 \pm 0.004$ & $0.82 \pm 0.33$ & $6.21 \pm 0.81$ & $8.49 \pm 0.81$ \\
\hline $\begin{array}{l}\text { P. granatum }(250 \\
\mathrm{mg} / \mathrm{kg})+(\text { GalN })\end{array}$ & $0.172 \pm 0.02 *$ & $0.457 \pm 0.25^{*}$ & $2.93 \pm 0.78$ & $2.99 \pm 0.73^{*}$ \\
\hline $\begin{array}{l}\text { P. granatum }(500 \\
\mathrm{mg} / \mathrm{kg})+(\text { GalN })\end{array}$ & $0.094 \pm 0.02^{* *}$ & $0.719 \pm 0.30^{* *}$ & $5.59 \pm 1.15^{* *}$ & $6.96 \pm 0.89 * *$ \\
\hline $\begin{array}{l}\text { Positive Control } \\
\text { (Silymarin) }\end{array}$ & $0.087 \pm 0.01^{* *}$ & $0.788 \pm 0.18^{* *}$ & $5.99 \pm 0.97^{* *}$ & $8.11 \pm 1.77^{* *}$ \\
\hline
\end{tabular}

Significant value: ${ }^{\Psi} \mathrm{P}<0.01$ Vs normal control, ${ }^{*} \mathrm{P}<0.05 ;{ }^{* *} \mathrm{P}<0.01$ Vs toxic control, One way ANOVA followed by Dunett's Test, TBARs (thiobarbituric acid reactive substances), GSH (glutathione), SOD (superoxide dismutase) and CAT (catalase), MDA (malondialdehyde), U/mg (unit per miligrams).

\section{DISCUSSION}

Liver injuries induced by D-GalN are the best-characterized system of xenobiotic induced hepatotoxicity and commonly used models for the screening of antihepatotoxic and/or hepatoprotective activities of drugs. The changes associated with D-GalN induced liver damage are similar to that of acute viral hepatitis $[40,41]$. Hence, D-GalN mediated hepatotoxicity was chosen as the experimental model. DGalN acts directly or indirectly and alters antioxidant status that makes certain organs, more susceptible to oxidative stress. Several studies have shown that D-GalN causes alteration of liver marker enzymes [42]. The toxicity of D-GalN results from inhibition of RNA and protein synthesis in the liver. The metabolism of D-GalN may deplete several uracil nucleotides including UDP-glucose, UDPgalactose and UTP, which trapped in the formation of uridine-dip hosho D-galactosamine. Accumulation of UDP-sugar nucleotide may contribute to the change in the rough endoplasmic reticulum and to the disturbance of protein metabolism $[40,41]$.

Phenolic compounds are known to be powerful chain breaking antioxidants and are important constituents of plants. Phenolic compounds may contribute directly to antioxidative action [43]. It has been recognised that flavonoids show antioxidant activity and their effects on human nutrition and health are considerable. Rutin and quercetin are flavonoids which is a very potent antioxidant, present in P. granatum fruit [44]. Antioxidants may offer resistance against oxidative stress by scavenging free radicals, inhibiting lipid peroxidation and by other mechanisms and thereby help in preventing the free radical induced diseases.

Since the antioxidant activity is important in providing protection against hepatic damage [45], in the present study, we have attempted to demonstrate the hepatoprotective activity of the extract of $P$. granatum through antioxidant activity. The in vitro assay provides an indication of effective results for aqueous extract of P. granatum fruit as compared to metanolic extract which further helpful in the selection of aqueous extract for in vivo study.

In the present research the elevated level of AST, ALT, ALP, and bilirubin levels induced by D-GalN administration was significantly reduced by aqueous extract of $P$. granatum fruit pre-treatment suggesting that its hepatoprotective activity might be due its effect against cellular leakage and loss of functional integrity of the cell membrane. GSH is an important endogenous antioxidant system that is found in particularly high concentration in liver and it is known to have key functions in protective processes. The reduced form of GSH becomes readily oxidized to GSSG on interacting with free radicals. Excessive production of free radicals resulted in the oxidative stress, which leads to damage of macromolecules and can induce lipid peroxidation in vivo. Elevation of GSH level by $P$. granatum shows its protective effects against oxidative stresses induced GSH depletion [46].

In our study, D-GalN treatment produced the elevation in the levels of TBARs and depletion in GSH, SOD and CAT. Pre-treatment of the rats with aqueous extract of $P$. granatum fruit significantly reduced the elevated levels of TBARs and increased the concentration of GSH, SOD and CAT. The $500 \mathrm{mg} / \mathrm{kg}$ dose of P. granatum showed more pronounced effects as compared to other doses $(250 \mathrm{mg} / \mathrm{kg})$, as shown by percent protection indicating improved metabolic activity and cellular stability. In summary, this investigation showed that the $P$. granatum fruit at a higher dose $(500 \mathrm{mg} / \mathrm{kg})$ possesses considerable protective effect against D-GalN induced liver injury. This protective effect of aqueous extract might be due to its antioxidant property.

\section{CONCLUSION}

From the results of the current investigation, it can be concluded that aqueous extract of $P$. granatum fruit has the ability to change the levels of enzymatic antioxidant parameters and significantly increase the endogenous antioxidant defense mechanisms in D-GalN induced hepatotoxicity. Our finding also showed that aqueous extract of $P$. granatum fruit treatment significantly normalizes the changes in serum markers of D-GalN treated rats. From the results obtained, we suggested that aqueous extract of $P$. granatum fruit may be developed as an effective hepatoprotective agent.

\section{AUTHORS CONTRIBUTION}

Most of experimental part of the work and writing of the manuscript was done by the first author Mohd Amir. In vitro study by MTT assay was done by Mohd Nasar Mallick. Before submission reading and correction of the manuscript was done by Niyaz Ahmadand Abuzer Ali. Design of the research work was done by corresponding author Dr. Mohd Mujeeb (Main Supervisor). Dr. Sayeed Ahmad and Dr. Mohd Akhtar was Co-supervisor.

\section{CONFLICT OF INTERESTS}

Declared none

\section{REFERENCES}

1. Ward FM, Daly MJ. Hepatic disease. In: Clinical pharmacy and therapeutics. Walker R, C Edwards. Eds. Churchill Livingstone, New York; 1999. p. 195-212.

2. Sharma A, Chakraborti KK, Handa SS. Anti-hepatotoxic activity of some Indian herbal formulations as compared to silymarin. Fitoterapia 1991;62:229-35.

3. Subramonium A, Pushpangadan P. Development of phytomedicines for liver diseases. Indian J Pharmacol 1999;31:166-75.

4. Sugiyama K, He P, Wada S, Saeki S. Teas and other beverages suppress D-galactosamine induced liver injury in rats. J Nutr 1999;129:1361-7.

5. Wills PJ, Asha VV. Protective effect of Lygodium flexuosum (L.) Sw. (Lygodiaceae) against D-galactosamine induced liver injury in rats. J Ethnopharmacol 2006;108:116-23.

6. Jonker AM, Dijkhuis FW, Boes A, Hardonk MJ, Grond J. Immunohistochemical study of extracellular matrix in acute DGalactosamine hepatitis in rats. Hepatology 1992;15:423-31.

7. Keppler DO, Pausch J, Decker K. Selective uridine triphosphate deficiency induced by D-galactosamine in liver and reversed by pyrimidine nucleotide precursors. Effect on ribonucleic acid synthesis. J Biol Chem 1974;246:211-6. 
8. Himaja N, Neelufar SS. Herbal wealth for hepatotoxicity: a review. Asian J Pharm Clin Res 2015;8:3-9.

9. Harde H, Schumacher W, Firbas F, Deffer D. Strasburg's Textbook of Botany. Chaucer, London; 1970.

10. Biale JB. Respiration and ripening in fruitsretrospect and prospect. In: J Friend, MJ Rhodes. Recent advances in the biochemistry of fruits and vegetables. London: Academic Press; 1981. p. 1-39.

11. Hodgson RW. The pomegranate. Bull Calif Agric Exp Stn 1917;276:163-92

12. La Rue JH. Growing pomegranate in california Univ of Calif. Agric Expt Sta Lflt; 1969. p. 305.

13. Nagy P, Shaw PE, Wordowski WF. Fruit of tropical and subtropical origin. Florida Science Source, Florida, USA; 1990. p. 328-47.

14. De Nigris F, Balestrieri ML, Williams-Ignaro SD, Armiento FP, Fiorito C, Ignaro LJ. The influence of pomegranate fruit extract in comparison to regular pomegranate juice and seed oil on nitric oxide and arterial function in obese Zucker rats. Nitric Oxide 2007;17:50-4.

15. Sudheesh S, Presannakumar G, Vijaya Kumar S, Vijayalakshmi NR. Hypolipidemic effect of flavonoids from Solanum melongean. Plant Foods Hum Nutr 1997;51:321-30.

16. Gil MI, Tomas-Barberan FA, Hess-Pierce B, Holcroft DM, Kader AA. Antioxidant activity of pomegranate juice and its relationship with phenolic composition and processing. J Agric Food Chem 2000;48:4581-9.

17. Kulkarni AP, Aradhya SM, Divakar S. Isolation and identification of a radical scavenging antioxidant punicalagin from pith and carpellary membrane of pomegranate fruit. Food Chem 2004;87:551-7.

18. Gil MI, Garcia-Viguera C, Artes F, Tomas-Barberan FA. Changes in pomegranate juice pigmentation during ripening. J Sci Food Agric 1995;5:77-81.

19. Richa T, Gaurav S, Nakuleshwar DJ, Ekta M. Indian medicinal plants as an effective antimicrobial agent. J Crit Rev 2016;3:69-71.

20. Afaq F, Saleem M, Mukhtar H. Pomegranate fruit extract is a novel agent for cancer chemoprevention; studies in mouse skin. 2nd annual AACR International Conference on Frontiers in Cancer Prevention Res; 2003. p. 135-42.

21. Naqvi SA, Khan MS, Vohora SB. Antibacterial, antifungal, and antihelminthic investigations on Indian medicinal plants. Fitoterapia 1991;62:221-8.

22. Lad V, Frawley D. The Yoga of Herbs. Santa Fe, NM: Lotus Press; 1986. p. 135-6.

23. Caceres A, Giron LM, Alvarado SR, Torres MF. Screening of antimicrobial activity of plants popularly used in Guatemala for treatment of dermatomucosal diseases. J Ethnopharmacol 1987;20:223-37.

24. Saxena A, Vikram NK. Role of selected Indian plants in management of type 2 diabetes: a review. J Alternative Complementary Med 2004;10:369-78.

25. Amir M, Khan A, Mujeeb M, Ahmad A, Usmani S, Akhtar M. Phytochemical analysis and in vitro antioxidant activity of Zingiber officinale. Free Radicals Antioxid 2011;1:75-81.

26. Padalia H, Moteriya $P$, Satasiya $R$, Chanda S. In vitro free radical scavenging activity and flavonoid content of Nerium Indicum, Pelto Phorampterocarpum and Rosa Spps. flower extracts. Asian J Pharm Clin Res 2015;8:91-7.

27. Hae Ung L, Eun Ah B, Myung Joo H, Nam-Jae K, Dong-Hyun K. Hepatoprotective effect of ginsenoside $\mathrm{Rb} 1$ and compound $\mathrm{K}$ on tert-butyl hydroperoxide-induced liver injury. Liver Int 2005;25:1069-73.

28. OECD. Eleventh Addendum to the, OECD, guidelines for the testing of chemicals organization for economical co-operation and development. Paris: 2000. Jun, Acute oral toxicity. Acute oral toxic class method guideline 423 adopted 23.03.1996; 2002.

29. Ghosh MN. Fundamentals of experimental pharmacology. IInd edn. Scientific Book Agency, Calcutta; 1984. p. 153-7.

30. Najmi AK, Pillai KK, Pal SN, Aqil M. Free radical scavenging and hepatoprotective activity of jigrine against galactosamine induced hepatopathy in rats. J Ethnopharmacol 2005;97:521-5.

31. Reitman S, Franfel S. A colorimetric method for the determination of serum glutamic oxalacetic and glutamic pyruvic transaminases. Am J Pathol 1957;28:56-9.

32. Duma BT. Determination of total protein and albumin in serum. Clin Chem Acta 1971;31:87-96.

33. Malloy HT, Evelyn KA. The determination of bilirubin with the photoelectric colourimeter. J Biol Chem 1937;119:481-90.

34. Kind PRN, King EJ. Estimation of plasma phosphatase by determination of hydrolysed phenol with amino-antipyrine. J Clin Pathol 1954;7:322-6.

35. Ohkawa H, Ohishi N, Yagi K. Assay for lipid peroxides in animal tissues by thiobarbituric acid reaction. Anal Biochem 1979;95:351-8.

36. Sedlak J, Lindsay RN. Estimation of total protein found and non protein sulphydryl group in tissue with ellmas reagent. Anal Biochem 1968;25:192-205.

37. Marklund S, Marklund G. Involvement of the superoxide anion radical in the autoxidation of pyrogallol and a convenient assay for superoxide dismutase. Eur J Biochem 1974;3:469-74.

38. Claiborne A. Catalase activity. In; Greenwald RA. ed. Handbook of Methods for Oxygen Radical Research. CRC Press: Boca Raton; 1985. p. 283-4.

39. Luna LG. Manual of Histology, Staining Methods of Armed Forces, Institute of Pathology. 3rd ed. McGraw Hill Book Co., New York; 1968. p. 43.

40. Chaung SS, Lin CC, Lin J, Yu KH, Hsu YF, Yen MH. The hepatoprotective effects of Limonium sinense against carbon tetrachloride and beta-galactosamine intoxication in rats. Phytother Res 2003;17:784-91.

41. Nakagiri R, Hashizume E, Kayahashi S, Sakai Y, Kamiya T. Suppression by hydrangeae dulcis folium of D-galactosamine induced liver injury in vitro and in vivo. Biosci Biotechnol Biochem 2003;67:2641-3.

42. Tang XH, Gao L, Gao J, Fan YM, Xu LZ, Zhao XN, et al. Mechanisms of hepatoprotection of Terminalia catappa $\mathrm{L}$. extract on D-Galactosamine-induced liver damage. Am J Chin Med 2004;32:509-19.

43. Anindita B, Bithin M, Sandip M, Kausik C, Tapan S. In vitro antidiabetic and anti-oxidant activities of ethanol extract of Tinospora Sinensis. Int J Curr Pharm Res 2017;9:42-7.

44. Amir M, Mujeeb M, Ahmad S, Akhtar M, Ashraf K. Design expert-supported development and validation of HPTLC method: an application in simultaneous estimation of quercetin and rutin in Punica granatum, Tamarindus indica and Prunus domestica. Pharm Methods 2013;4:62-7.

45. Poli G. Liver damage due to free radicals. $\mathrm{Br}$ Med Bull 1993;49:604-20.

46. Sinclair AJ, Barnett AH, Lunie J. Free radical and auto-oxidant systems in health and disease. J Appl Med 1991;17:409-12.

\section{How to cite this article}

- Mohd Amir, Mohd Nasar Mallick, Niyaz Ahmad, Abuzer Ali, Sayeed Ahmad, Mohd Akhtar, Mohd Mujeeb. Hepatoprotective effects of Punica granatum fruit against D-galactosamineinduced hepatotoxicity in rats: In vitro and In vivo studies. Int J Pharm Pharm Sci 2017;9(8):168-172. 